\title{
THE USE OF ANTIFUNGAL ACTIVITY OF Lactobacillus plantarum DSMZ20191 IN BIOPRESERVATION OF DIETS USED FOR FEEDING OF THE NILE TILAPIA(Oreochroms niloticus) FINGERLINGS
}

Salha G. Desouky

Faculty of Science, Department of Botany and Microbiology, Suez Univ, Egypt.

\begin{abstract}
This study was designed to examine the antifungal activity of Lactobacillus Plantarum DSMZ 20191 on a variety of molds which normally contaminated the fish diet and my cause it's deterioration and also affect it's shelf life. We used different concentration of the antifungal metabolites $(1,2,3,4$ and $5 \mathrm{ml} / 100 \mathrm{~g}$ of the fish diets) to demonstrate it's role in inhibition of fungal growth during storage of fish diets. According to our study Lb. plantarum DSMZ 20191exhibit high activity against Aspergillus sp. which contaminated animal fish diet especially at concentration of $5 \%$, while in plant diet the antifungal activity against Aspergillus sp., Fusarium sp. and Penicillum sp.was lower. Finally the activity against Aspergillus sp. and Fusarium sp.in mixed fish diet was moderate.In conclusion $L A B$ can be used in biopreservation due to their antifungal activity against a variety of molds which contaminate different food and feed and can cause serious deterioration and this can eliminate the use of chemical preservatives.
\end{abstract}

Keywords: Lactic acid bacteria, Lb. plantarum and Biopreservation

\section{INTRODUCTION}

Food and feed spoiling moulds and yeasts cause great economic losses worldwide. Furthermore, the presence of moulds with the concomitant production of allergenic spores and possibly mycotoxins makes them serious potential health hazards (Pitt and Hocking, 1999). Aflatoxins, part of a large group called mycotoxins, are toxic substances produced as a result of mold growing on grain, feedstuff and other foods. Mycotoxigenic fungi such as Fusarium and Penicillium are serious hazard for human health (Dalie et al., 2009). Filamentous moulds and yeasts are common spoilage organisms of food products as stored crops, bread and feed such as hay and silage (Bullerman, 1977). During the last years there has been a growing interest in biopreservation to prevent spoilage and extend the shelf life of foods (Stiles, 1996). The reduction of mould and yeast growth in food and feed production and storage is thus of primary importance and there is great interest in developing efficient and safe strategies for this purpose. The application of biopreservation has received much attention in recent years. Lactic acid bacteria $(\mathrm{LAB})$ are known to produce different antimicrobial compounds and are important in the biopreservation of food and feed, Lindgren and Dobrogosz (1990) and (Messens and de Vuyst, 2002). LAB are of special interest as biopreservation organisms since they have a long history of use in food and are 'generally regarded as safe' organisms. Their preserving effect mainly relates to the production of organic acids, i.e. lactic and acetic acid (Stiles, 1996), but bacteriocins, produced by some strains, are also of importance (Dodd and Gasson,1994). The majority of the large numbers of 
reports on antimicrobial activity of $L A B$ have focused on antibacterial effects (Dodd and Gasson, 1994) while reports on antifungal effects are few. Lavermicocca et al., (2000) reported on the production of the antifungal compounds phenyllactic acid and 4-hydroxyphenyllactic acid by a sourdough Lactobacillus plantarum strain. In addition, bacteriocin-like substances and other low molecular mass compounds produced by LAB have been reported as antifungal (Niku-paavola et al., 1999) and (Okkeret al., 1999). Lactobacillus coryniformis strain Si3 can produce a proteinaceous antifungal compound (Magnusson and Schnurer, 2001).Strom et al., (2002) also identified antifungal cyclic dipeptides from a silage $L$. plantarum strain. The application of LAB with the simultaneous control of factors that affect the fungal growth can help to minimize food spoilage, (Belal et al., 2013). The aim of this study is to demonstrate the role of lactic acid bacteria in inhibition of fungal growth due to the production of many antifungal metabolites which can be extracted and used in biopreservation of fish diets during 90 days of storage.

\section{Culture:-}

\section{MATERIALS AND METHOD}

The investigated bacterial strain (Lactobacillus plantarum DSMZ 20191) was obtained from the collection of food Science Department, Faculty of Agriculture,Ain Shams University, Egypt. The culture re activated on MRS broth medium.

\section{Production of the antifungal metabolite(s):-}

The bacterial strain was cultivated on $2000 \mathrm{ml}$ of de Man, Rogosa and Sharpe (MRS)(de Man et al., 1960) broth medium divided into 20 flask, each containing $100 \mathrm{ml}$ and inoculated with $2 \%$ of the bacterial cell suspension, then incubated at

$32^{\circ} \mathrm{C}$ for $48 \mathrm{~h}$.

\section{Extraction of antifungal metabolite(s):-}

A cell free extract was obtained by centrifugation at $\left(10.000 \mathrm{xg}\right.$ at $4^{\circ} \mathrm{C}$ for $20 \mathrm{~min}$ ) the extract was adjusted to $\mathrm{pH} 7.0$ by means of $1 \mathrm{M} \mathrm{NaOH}$ to exclude the effect of organic acids. The extract then filtrated through a $0.2 \mathrm{~mm}$ pore size cellulose acetate filter (Schillinger and Luke, 1989). The extract then dialyzed for $12 \mathrm{~h}$ and added to the fish diet by volume of $(1-2-3-4$ and $5 \mathrm{ml} / 100 \mathrm{~g}$ of the fish diet and then the different diets were stored in sterilized plastic bags at $4^{\circ} \mathrm{C}$.

Testing of antifungal activity:-

The activity was investigated by using the pour plate method using potato dextrose agar medium (PDA), in which serial dilution was carried out using $0.8 \% \mathrm{Nacl}$ sterilized saline solution and only dilution of $10^{4}$ was selected for total fungal count in each volume Volumes of the antifungal metabolites then $1 \mathrm{ml}$ of this dilution was used for testing the antifungal activity, then the plates were incubated at $32^{\circ} \mathrm{C}$ for 3 days. The total count of fungal colonies was then carried out for different plates.

The experimental feeds :-

Three diets were formulated, the first diet was the dietary protein derived mostly from animal sources (fish meal, meat meal, bone meal and poultry by product meal).The second diet was derived from plant sources (soybean meal, 
sunflower meal and corn gluten meal. Finally the third diet was a mixture of animal and plant.

Preparation of diets:

All ingredients were prepared by successive grinding through a commercial feed grinder (1/ 16 mesh), without any additional heat. Before mixing we add different concentrations of the antifungal supernatant (1, 2, 3, 4 and 5\%) to all diets. Then diets were mixed mechanically by horizontal mixer, the feed mixture was processed into a California pellet meal (CPM) machine.

\section{RESULTS AND DISCUSSION}

\section{Demonstration of antifungal activity}

Penicillum and Aspergillus species have been reported as spoilage organisms during storage of food and feeds and Fusarium species are often found on cereal grains, where they might produce mycotoxins (Filtenborg et al., 1996). Studies on the effect of LAB on fungi are complicated by the fact that some fungi are sensitive to the normal by products of lactic acid bacteria (LAB) metabolism, most notably lactic and acetic acids (Bonesteroo et al., 1993). In our study we avoided the effect of organic acids to demonstrate the effect of low molecular weight pertinacious antifungal metabolitesfound in the extract produced by Lactobacillus plantarum DSMZ 20191 against moulds contaminated plant animal and mixed fish diet.

Fig. (1) demonstrate antifungal activity of Lactobacillus plantarum DSMZ 20191 against moulds contaminated animal fish diet. According to microscopic examination the isolated moulds are belonging only to Aspergillus $s p$. At Zero time (A) the antifungal activity was estimated, at $1 \%$ it was recorded $(75 \%)$, while the concentrations of $(2,3,4$, and $5 \%)$ were recorded activity of $100 \%$. The antifungal activity at 15 and 30 days of storage, (B) was recorded the same results, at $1 \%$ of our extract the activity was $(72 \%)$, also the activity at $2 \%$ recorded $(78 \%)$. Finally the antifungal activity at (3-4 and $5 \%$ ) recorded $100 \%$. After 45 days,(C) the antifungal activity was decreased to recorded at $1 \%(68 \%)$, on the other hand the activity at $2 \%$ was (70\%). Finally the activity at 4 and $5 \%$ was recorded $100 \%$. Moreover, after 60 days of storage, (D) further decrease in activity was recorded. The activity at $1 \%$ was $(66 \%)$, while at $2 \%$ it was $(70 \%)$. Finally at the concentrations of $3-4 \%$ the activity recorded $(73 \%),(75 \%)$ and at concentration of $5 \%$ the activity was $100 \%$. The antifungal activity after75 days, (E) recorded more decrease at $1 \%$ it was $(63 \%)$, while at $2 \%$ it was $(67 \%)$ furthermore the activity recorded $(74 \%),(77 \%)$ and $(81 \%)$ for $3-4$ and $5 \%$ respectively. Finally at 90 days of storage, $(F)$ the antifungal activity recorded $(61 \%)$.LAB are well known for their antifungal activity, which is related to the production of a variety of compounds including acids, alcohols, carbon dioxide, diacetyl, hydrogen peroxide, bacteriocines and cyclic peptide (Gerez et al., 2009). These compounds were added to several foods in order to conserve them from food- borne and spoilage organisms (El-Ziney and Debevere, 1998).

The plant fish diet is highly contaminated by moulds and the isolated molds were belonging to Aspergillus sp., Fusarium sp. and Penicillium sp. Fig.2 (A) demonstrating that, the activity at $1 \%$ was $(38 \%)$ at Zero time, by increasing the volume to $2 \%$, the antifungal activity was raised to $(45 \%)$. Additionally the activity at 
(3,4 and 5\%) was 50, 41 and $48 \%$ respectively. After that, the results at 15 and 30 days (B), were the same, at the start the activity was (45\%) at $1 \%$, then it was recorded $(53 \%)$ at $2 \%$. The activity at $3 \%$ was $(58 \%)$, on the other hand the activity at 4 and $5 \%$ was $(64 \%)$ and $(77 \%)$. Decrease in activity toke place after 45 days (C) and it was (35\%) at $1 \%$. At $2 \%$ the activity up to $(44 \%)$, moreover the activity at 3,4 and $5 \%$ was (53\%), (66\%) and (75\%) respectively. The activity was little decreased after 60 days (D) and recorded at $1 \%(36 \%)$. As noted from the Fig. the antifungal activity was increased to (44\%) at $2 \%$, the activity again increased to $(52 \%)$ at $3 \%$. Finally the activity at 4 and $5 \%$ was $(61 \%),(73 \%)$ respectively. There was a little decrease in activity after 75 days of diet storage (E) and the activity recorded at $1 \%(34 \%)$, and at $2 \%(41 \%)$. By increasing the concentration to $3 \%$, the activity raised to (50\%). Furthermore the activity at 4 and $5 \%$ increased to $(54 \%)$ and $(70 \%)$ respectively. After 90 days of storage, (F) the activity recorded $(33 \%)$ at $1 \%$, at $2 \%$ the activity was (39\%), Finally the activity at 3, 4 . and $5 \%$ recorded (48\%), (58\%) and (65\%) respectively .Aspergillus and Penicillium species are the most common spoilage fungi for many foods and feeds while Fusarium species are reported to attack cereal grains in the field (Samson et al., 2000). The antifungal activity of strain $\mathrm{Lb}$. plantarum against Aspergillus $s p$. And fusarium $s p$. was reported by many researchers . Hikara et al., (1994) reported on the discovery of strain of $L b$. plantarum ( $L b$. planetarium 601) with antifungal capabilities towards Fusarium sp. And Aspergillus niger.

Fig. (3) demonstrated the antifungal activity of metabolites added to the mixed fish diet and it recorded good activity against the contaminants of Aspergillus $s p$. and Fusarium sp. The activity at Zero time (A) was (40\%) at $1 \%$, by increasing the concentration the activity gradually increased. At $2 \%$ the activity was $(49 \%)$. Also at $3 \%$ the activity recorded $(56 \%)$. The antifungal activity was $(65 \%)$ and $(66 \%)$ for 4 and $5 \%$ respectively. After 15 days of storage $(B)$, the activity was little increased at the different concentrations and recorded $(46 \%)$ at $1 \%$. On the other hand the activity at $2 \%$ raised to be $(53 \%)$. Furthermore the activity at 3,4 and $5 \%$ was $(61 \%),(66 \%)$ and $(90,87,84,75$ and $60 \%)$ respectively. By time the activity was little decreased after 30 days (C) and still as it was after 45 days. The activity at $1 \%$ was $(44 \%)$, while the activity at $2 \%$ recorded $(50 \%)$, the activity further increased to (53\%), (58\%) and (68\%) for 3, 4 and $5 \%$. After 60 days (D), the activity decreased to (42\%) at $1 \%$ and it was $(48 \%),(51 \%)$ and $(56 \%)$ at 2 , $3,4 \%$. Moreover the activity at $5 \%$ was $(66 \%)$. On the other hand the activity little down again at 75 and 90 days $(E)$, at $1 \%$ the activity was $(40 \%)$, the activity at $2 \%$ up to $(46 \%)$, at 3,4 and $5 \%$ the activity was $(49 \%),(55 \%)$ and $(62 \%)$. From the previous results we can say that our tested bacterium relatively exhibited high antifungal activity against molds contaminated mixed fish diet at Zero and 15 days, then the activity slightly decreased by time but we can considered it good activity at high concentration of the antifungal extract. The use of protein-like compounds are preferred over the use of acids because their activity is present over a wide range of $\mathrm{pH}$ and they are heat stable (Muhialdin et al., 2011). Lavermicocca et al., (2000) could isolated a metabolite from $L b$. plantarum strain 21Bwhich exhibited abroad spectrum activity against Aspergillus flavus and Aspergillus niger. In a related study carried out by Latilla et al., (2002) they studied the antifungal potential Lb. plantarum strain (E98) against Fusarium sp.The results indicated that Lb.plantarum cell free extracts were effective against fusarium $s p$. 
Fig.(1): Demonstration of antifungal activity of Lactobacillus plantarum DSMZ 20191 against fungi contaminated animal fish diet using different metabolites concentrations.

where: $A c=$ Control sample, $A 1=1 \%, A 2=2 \%$, $A 3=3 \%, A 4=4 \%$ and $A 5=5 \%$ 
Fig.(2): Demonstration of antifungal activity of Lactobacillus plantarum DSMZ 20191 against fungi contaminated plant fish diet by using different metabolites concentrations.

Where: $\mathrm{Pc}=$ control, $\mathrm{P} 1=1 \%, \mathrm{P} 2=2 \%, \mathrm{P} 3=3 \%, \mathrm{P} 4=4 \%$ and $\mathrm{P} 5=5 \%$ 
Fig.(3): Demonstration of antifungal activity of Lactobacillus plantarum DSMZ 20191 against fungi contaminated mixed fish diet by using different metabolites concentrations.

Where: $M c=$ control, $M 1=1 \%, M 2=2 \%, M 3=3 \%, M 4=4 \%$ and $M 5=5 \%$ 


\section{CONCLUSION}

Chemical preservatives and Fungicides which used to inhibit fungal growth and also mycotoxin production in different food and feed can be considered as serious potential health hazards for consumers. In addition to the effect of these chemicals on environment along with problems of microbial resistance favor the need for alternative methods in controlling fungal growth. Application of $L A B$ in biopreservation of different food and feed is now has a very good interest.

\section{REFERENCES}

Belal J. Muhialdin, Zaiton Hassan and Nazamid Saari (2013): Lactic Acid Bacteria in Biopreservation and the Enhancement of Functional Quality of Bread, chapter 6. http: // dx.doi.org/ 10.5772151626 .

Bonestroo, M.H.; Dewit, J.C. ;kusters, B.J.M. and Rornbouts, P.M. (1993): Inhibition of the growth of yeasts in fermented salad.Inter. J. Food Microbiol., 17, 311-320.

Bullerman, L.B. (1977): Incidence and control of mycotoxin producing molds in domestic and imported cheeses. Annales de la nutrition et de 1" alimenation, 31,435-46.

Dalie, D. K. D., Deschamps, A. M. and Richard-Forget, F. (2009): LABpotential for control of mould growth and mycotoxins. Areview. Food Control, 21: 370-380.

de Man, J.D.; Rogosa, M.; Sharpe, M.E. (1960): "A Medium for the Cultivation of Lactobacilli". J. Appl. Bact 23 (130-135).

Dodd, H.M. and Gasson, M.J. (1994): Bacteriocins of lactic acid bacteria. In: Genetics and Biotechnology of Lactic Acid Bacteria (Gasson, M.J. and De Vos, W.M., Eds.), pp. 211-251. Blackie Academic and Professional, London.

EL-Ziney, M. G. and Debevere, J.M. (1998): The effect of reuterin on Listeria monocytogenes and E. coli $\mathrm{O} 157: \mathrm{H} 7$ in milk and cottage cheese. J. Food Protection, 61: 1275-1280.

Filtenborg, O. ;Frisvad, J.C. and Thrane, u. (1996): Moulds in food spoilage, Inter. J. Food Microbiol., 33, 85-102.

Gerez, C.L., Torino, M.I., Rollan, G. and Font de valdez, G (2009): Prevention of bread moulds spoilage by using lactic acid bacteria with antifungal properties. Food Control, 20: 144-148.

Haikara, H. ;Skytt, E. ; Raaske, L. and Mattila-sandholm, T. (1994): The Microbial activites of Lactobacillus and pediococcus species in combination with other starters against process contaminates and pathogens. Poster presentation at Lactic 94, an inter. Symposium on lactic acid bacteria, caen, Normandy, France.

Laitila, A. ;Alakomi, H.L. ; Raaska, L. ; Mattila-Sandholm, t. ; Hikara, A. (2002): Lactobacillus plantarum strains gainst Fusarium moulds in vitro and in malting of barley. J. App. Microbiol., 93 (4), 566-576. 
Lavermicocca, P., Valerio, F., Evidente, A., Lazzaroni, S., Corsetti, A., Gobetti, M. (2000): Purification and characterization of novel antifungal compounds from the sourdough Lactobacillus plantarum strain 21B. Appl. Environ. Microbiol. 66, 4084-4090.

Lindgren, S.E., Dobrogosz, W.J. (1990): Antagonistic activities of lactic acid bacteria in food and feed fermentations. FEMS Microbiol. Rev. 87, 149-164.

Magnusson, J., Schnürer, J. (2001): Lactobacillus coryniformis subsp. coryniformis strain $\mathrm{Si} 3$ produces a broad-spectrum proteinaceous antifungal compound. Appl. Environ. Microbiol. 67.

Messens, W., de Vuyst, L. (2002): Inhibitory substances produced by Lactobacilli isolated from sourdoughs - a review. Int. J. Food Microbiol. 72, 31-43.

Muhialdin, B. J., Hassan, Z. and Sadon, S. K.(2011): Antifungal Activity of Lactobacillus fermentum Teoot, Pediococcus pentosaceus Teolo, $L b$. pentosus G004 and Lb. paracasi D5 on selected foods. J. Science, 76: 493-499.

Niku-paavola, M.-L., Laitila, A., Mattila-Sandholm, T., Haikara, A. (1999): New types of antimicrobial compounds produced by Lactobacillus plantarum. J. Appl. Microbiol. 86, 29-35.

Okkers, D.J., Dicks, L.M.T., Silvester, M., Joubert, J.J., Odendaal,H.J. (1999): Characterization of pentocin TV35b, a bacteriocin-like peptide isolated from Lactobacillus pentosus with a fungistatic effect on Candida albicans. J. Appl. Microbiol. 87, 726-734.

Pitt, J.I. and Hocking, A.D. (1999): Fungi and Food Spoilage. Chapman and Hall, New York.

Samson, R. A., Hoekstra, E. S., Frisvad, J. C. and Filtenborg, O. (2000): Introduction to food and air born fungi. $6^{\text {th }}$ ed. Central bureau boor schimmel culture.

Schillinger, V. and S.K. Luke, (1989): Antimicrobial activity of Lactobacillus saki isolated from meat. Applied Environmental Microbiology, 55: 19011906.

Stiles, M.E.(1996): Biopreservation by Lactic acid bacteria. Antonie Van Leeuwenhoek, 70, 331-345.

Strom, K., Sjogren, J., Broberg, A. and Schnurer, J. (2002): Lactobacillus plantarum MiLAB 393 produces the antifungal cyclic dipeptides cyclo(LPhe-L-Pro) and cyclo (L-Phe-trans-4-OH-L-Pro) and phenyllactic acid. Appl. Environ. Microbiol 68, 4322-4327. 


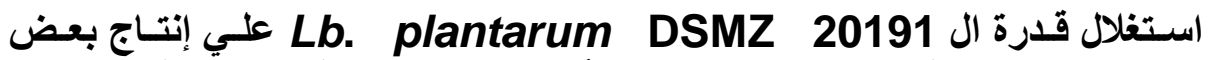
المضـادات الفطريـة في الحفظ الحيوي للأعلاف المستخذمة في تغذيـة إصبعيات البلطي (Oreochroms niloticus)

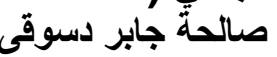
كلية العلوم, قسم النبات والميكروبيولوجي, جامعة السويس, مصر.

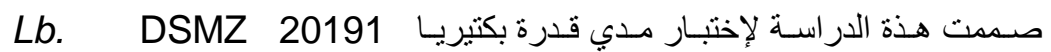
plantarum

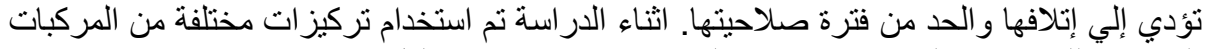

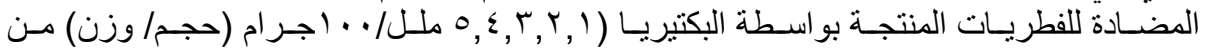

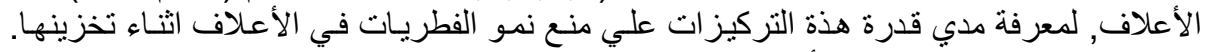

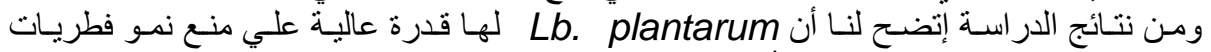

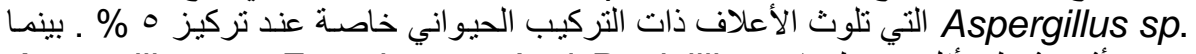

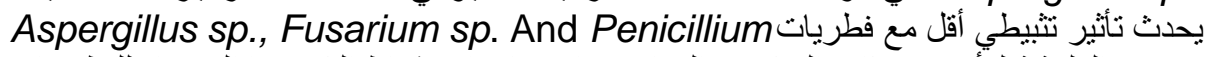

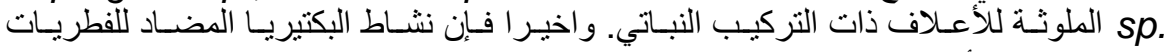
يوضح نأثير منوسط ضد في فطريات الأعلاف ذات التركيب الحيو اني - النباتي المختلط.

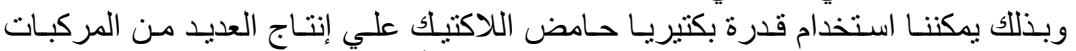

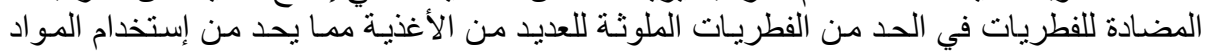
الحافظة الكيميائية واستبدالها بالحفظ الحن الحيوي. 